\title{
Effects of diets low in fat or essential fatty acids on the fatty acid composition of blood lipids of calves
}

\author{
BY D. SKLAN AND R. VOLCANI \\ Volcani Institute of Agricultural Research, Bet-Dagan, Israel \\ AND P. BUDOWSKI \\ Faculty of Agriculture, The Hebrew University of Ferusalem, Rehovot, Israel
}

$$
\text { (Received } 28 \text { April I971 - Accepted I3 September 1971) }
$$

\footnotetext{
I. Groups of newborn calves were fed on liquid diets which had fat contents ranging from 0.2 to $17 \%$ (dry-weight basis) and which provided linoleic acid in amounts ranging from 0.01 to $0.7 \%$ of the calorie intake. 'Two commercial milk replacers, high in fat $(17-18 \%)$ and linoleic acid $\left(3.4\right.$ and $5.0 \%$ of calories) were also given. All diets were given for at least $6_{5} \mathrm{~d}$. 2. Except for reduced feed utilization associated with the two diets lowest in fat $(0.2$ and $0.4 \%$ ), the calves developed normally, without signs of essential fatty acid deficiency.

3. The polyunsaturated fatty acid content of erythrocytes and plasma phospholipids and cholesteryl esters rose rapidly during the first few days on all diets. At $65 \mathrm{~d}$, these concentrations were higher than at birth and appeared generally to be related to the linoleic acid intake. However, in the low dietary linoleic acid range, the fat content of the diet also seemed to exert some influence. In no instance was there any indication of the appearance of $20: 3 \omega 9$, which is observed in other species under conditions of essential fatty acid deficiency.

4. Some of the experimental diets were given to weanling rats. There was a rapid fall in the polyunsaturated fatty acid content of erythrocyte lipids and plasma phospholipids and cholesteryl esters, accompanied by the appearance of $20: 3 \omega \mathrm{g}$.

5. These results suggest that calves on liquid diets have apparently a very low requirement for essential fatty acids.
}

The essential fatty acid (EFA) status of ruminants has not yet been adequately studied. It is well known that ruminant depot and milk fats, in contrast to fats of nonruminant animals, contain very small amounts of polyunsaturated fatty acids (PUFA), in spite of high dietary intakes of these compounds. This has been shown to be due to extensive hydrogenation caused by micro-organisms in the rumen. A detailed review on the subject has appeared recently (Viviani, 1970).

Leat ( 1966 ) reported very low concentrations of $18: 2$ and $18: 3$ in the plasma lipids of newborn calves, lambs and kids, in contrast to the high concentrations of PUFA in plasma phospholipids and cholesteryl esters of adult ruminants. He postulated the existence of a placental barrier and called attention to the presence in the plasma of newborn ruminants of a fatty acid which appeared to be $20: 3^{\omega 9}$, found only in EFAdeficient animals. Nevertheless, in a small number of studies in which pains were taken to exclude EFA from the diet, no typical deficiency signs could be observed. Thus, Lambert, Jacobson, Allen \& Zaletel (1954) reported the appearance of signs resembling EFA deficiency in calves receiving a diet very low in fat, but addition of hydrogenated fat to the diet seemed to alleviate these signs. Cunningham \& Loosli $(1954 a, b)$ reported that calves, lambs and kids died when fed on a diet rigorously free of fat, but small amounts of hydrogenated fat prevented death. Adams, Gullick- 
son, Gander \& Sautter (I959) fed calves on a diet containing $0.15 \%$ milk fat as the only source of fat for 5-6 months and observed no detrimental effects other than slightly decreased growth.

Recently, Noble, Steele \& Moore (I97I) studied the changes in plasma lipids of lambs during the first $8 \mathrm{~d}$ of life. One group of lambs which received a reconstituted milk powder containing $0.03 \%$ fat exhibited greatly retarded growth, and there was a clear increase in the triene:tetraene ratio of plasma lipids, indicative of EFA deficiency.

These reports raise the question of the apparently low requirement of the young ruminants for EFA. The object of the present study was to reinvestigate the effect of diets low in fat and EFA on the growth and fatty acid (FA) composition of calf lipids.

\section{EXPERIMENTAL}

\section{Calves and their diets}

Male calves of the Israeli-Friesian strain were separated from their mothers at birth and housed in separate stalls on straw bedding. All animals received 31 skimmed colostrum during the $24 \mathrm{~h}$ period following birth. This colostrum was prepared in advance from the first post-partum milking by centrifugation at $2000 \mathrm{~g}$ for ro min and removal of the disc of solid fat formed on standing at $4^{\circ}$ for $2 \mathrm{~h}$. During the first $3 \mathrm{~d}$ of life the calves were also given orally two doses, each containing 50000 i.u. retinol and 5000 i.u. cholecalciferol (Palmitlets; Chas. Pfizer Co. Inc., New York) and, by intramuscular injection, I g $\gamma$-globulin (Gammacombin; Dr E. Graub, Bern, SC, Switzerland).

After receiving the colostrum, the animals were transferred to the experimental diets. These were prepared by a local feed manufacturer (Premin Ltd, Tel Aviv) from skim-milk powder containing less than $0.2 \%$ fat, to which $3 \%$ of a concentrate supplying vitamins (fat-soluble and B complex) and minerals was added. The vitamin concentrate was devoid of EFA. The amount and type of fat added were varied in order to provide different levels of fat and EFA. The only emulsifier used was glyceryl monostearate, which contained no detectable unsaturated FA. The fats used in the experimental diets were coconut oil and four kinds of hydrogenated soya-bean oil (m.p. ranging from 47 to $49^{\circ}$ ). The molten fats containing the emulsifier were sprayed on to the basal ingredients, and the materials were thoroughly mixed. Two commercial milk replacers (Milkivit; Premin Ltd, Tel Aviv) were also used in the feeding experiments.

The compositions of the diets are presented in Table 1 . The concentration of fat ranged from 0.2 to $17.8 \%$, and the energy content was $4.1 \mathrm{I}-5 \cdot 17 \mathrm{kcal} / \mathrm{g}$. The percentages of PUFA in the total FA of the lipid extracts obtained from the diets are included in Table 2. The linoleic acid content ranged from $2 \cdot 1$ to $29.9 \%$ and contributed from 0.01 to $5.0 \%$ of the dietary calories. Minor amounts of linolenic acid were present in some diets. These values were obtained by gas-liquid chromatography under conditions which did not permit the separation of positional and geometrical isomers. However, at least $90 \%$ of the total PUFA thus determined in the different diets 
possessed the $c i s, c i s-1,4$-diene structure, as shown by the lipoxygenase assay (see below).

The dry milk replacers were dispersed in warm water at a concentration of $250 \mathrm{~g} / 1$ and offered once daily. Feed intake was closely similar for all groups, with differences not exceeding $10 \%$.

Since some nibbling of the straw used for bedding was observed, samples of straw were analysed and found to average $230 \mathrm{mg}$ linoleic acid $/ \mathrm{kg}$. There was no detectable linolenic acid.

Table I. Gross percentage composition of the milk replacer diets $\mathbf{I}-9$

\begin{tabular}{|c|c|c|c|c|c|c|c|}
\hline & $\mathbf{I}$ & 2 & 3 & 4 & 5 & $6,7,9$ & 8 \\
\hline Fat & 0.2 & 0.4 & $2 \cdot 5$ & $7 \cdot 1$ & I $2 \cdot 0$ & I $7 \cdot 0$ & $17 \cdot 8$ \\
\hline Protein & $32 \cdot 9$ & $32 \cdot 9$ & $32 \cdot 2$ & 30.5 & $28 \cdot 9$ & $27 \cdot 5$ & $27 \cdot 3$ \\
\hline Carbohydrate & $58 \cdot 2$ & $58 \cdot 0$ & $5^{6 \cdot 8}$ & 543 & $5 \mathrm{I} \cdot 4$ & $48 \cdot 2$ & $47 \cdot 6$ \\
\hline Ash & $8 \cdot 7$ & $8 \cdot 7$ & $8 \cdot 5$ & $8 \cdot \mathrm{I}$ & $7 \cdot 7$ & $7 \cdot 3$ & $7 \cdot 3$ \\
\hline \multicolumn{8}{|l|}{ Energy content } \\
\hline $\begin{array}{l}\mathrm{kcal} / \mathrm{g} \\
\mathrm{J} / \mathrm{g}\end{array}$ & $\begin{array}{r}4^{*} \text { I I } \\
\text { I7 } 200\end{array}$ & $\begin{array}{r}4 \cdot 12 \\
17250\end{array}$ & $\begin{array}{r}4 \cdot 27 \\
17870\end{array}$ & $\begin{array}{r}453 \\
18960\end{array}$ & $\begin{array}{c}4 \cdot 8 I \\
20130\end{array}$ & $\begin{array}{c}5 \cdot 13 \\
21470\end{array}$ & $\begin{array}{l}5.17 \\
2 \text { I } 640\end{array}$ \\
\hline
\end{tabular}

Rats and their diets

In some comparative experiments, male white albino rats of a mixed strain were separated from their mothers at $2 \mathrm{r} d$ and placed in cages with raised wire floors. In one experiment, groups of five rats were given diets 4,5 and 7 , as well as diet 5 supplemented with $0.9 \%$ safflower-seed oil. In a second experiment, three groups of twelve rats were fed on diets $I$ and 4 , and diet I supplemented with $0.9 \%$ safflower-seed oil.

\section{Sampling}

Blood samples were obtained from the jugular vein of calves $20 \mathrm{~h}$ after feeding, using oxalate as the anticoagulant. Subcutaneous fat samples were obtained by biopsy from the skinfolds of the breast. Tissues were obtained from calves that died at birth or that were slaughtered.

Rats were killed by a blow on the head, blood was taken from the heart, and other organs were sampled immediately. Plasma was separated by centrifugation at $7000 \mathrm{~g}$ for Io min, and erythrocytes were washed as described by Dodge \& Phillips (I967).

\section{Analytical methods}

Extraction of lipids. Plasma lipids were extracted by adding, under constant stirring, $5 \mathrm{ml}$ plasma to roo $\mathrm{ml}$ chloroform-methanol $(2: \mathrm{I}, \mathrm{v} / \mathrm{v})$. The mixture was allowed to stand at room temperature for $\mathrm{I} h$ and filtered. The solvent was removed under reduced pressure, and the residue was taken up in chloroform. Erythrocyte lipids were extracted according to the procedure of Dodge $\&$ Phillips (1967). Tissue samples were homogenized in a Virtis high-speed blender and lipids extracted with chloroformmethanol as described by Folch, Lees \& Stanley (1957).

Separation of lipid fractions. Liver and muscle phospholipids were separated by chromatography on a column $(3.5 \times 18 \mathrm{~cm})$ of activated silicic acid, using chloroform to remove the neutral lipids and methanol to elute the phospholipids. Plasma 
phospholipids and cholesteryl esters were separated from other lipids by thin-layer chromatography (TLC) on silica gel $\mathrm{GF}_{254}$ (E. Merck AG, Darmstadt) using light petroleum (b.p. 40-60\%)-diethyl ether 90: $10(\mathrm{v} / \mathrm{v})$ as the developing solvent. Triglycerides were obtained from subcutaneous tissue lipids by shaking the latter with chloroform and silicic acid, filtering and removing the solvent from the filtrate under reduced pressure.

Preparation of methyl esters and gas-liquid chromatography. Fatty acid methyl esters were prepared by refluxing the lipid fractions with $3 \%(\mathrm{w} / \mathrm{v})$ sulphuric acid in methanol, and were separated by gas-liquid chromatography on diethylene glycol succinate polyester as previously described (Sklan, Volcani \& Budowski, r97I).

Determination of PUFA possessing the cis,cis-1,4-diene structure. Portions of the chloroform-methanol extract of lipids were transferred to $100 \mathrm{ml}$ volumetric flasks, and the solvent was evaporated under a stream of nitrogen. The amount of FA containing at least two methylene-interrupted $c$ is double bonds was determined following the procedure described by MacGee (I959). This method is based on the lipoxygenaseinduced peroxidation of FA of the type referred to above, which causes a specific increase in absorbance at $234 \mathrm{~nm}$.

\section{Table 2. Polyunsaturated fatty acid content of dietary fats and weight gains of calves after $65 d$ on the experimental diets}

\begin{tabular}{|c|c|c|c|c|c|c|c|}
\hline \multirow[b]{2}{*}{$\begin{array}{c}\text { Diet } \\
\text { no. }\end{array}$} & \multirow[b]{2}{*}{ Main source of fat } & \multicolumn{2}{|c|}{$\begin{array}{c}\text { Dietary } \\
\text { PUFA }\end{array}$} & \multirow{2}{*}{$\begin{array}{c}\text { Dietary } \\
18: 2 \\
(\% \\
\text { calories })\end{array}$} & \multirow[b]{2}{*}{$\begin{array}{c}\text { No. } \\
\text { of } \\
\text { calves }\end{array}$} & \multirow[b]{2}{*}{$\begin{array}{l}\text { Daily wt gain* } \\
\text { (kg) }\end{array}$} & \multirow[b]{2}{*}{$\begin{array}{c}\text { Wt gain/calorie } \\
\text { intake* } \\
\text { (kg/Mcal) }\end{array}$} \\
\hline & & $\begin{array}{l}18: 2 \\
(\% \text { total }\end{array}$ & $\begin{array}{l}\text { I } 8: 3 \\
\text { FA) }\end{array}$ & & & & \\
\hline I & Milk & $2 \cdot I$ & 0.0 & $0.0 \mathrm{I}$ & 4 & $0.51 \pm 0.02$ & $0.129 \pm 0.005$ \\
\hline 2 & Milk + safflower-seed oil & $29 \cdot 9$ & $2 \cdot 6$ & 0.29 & 3 & $0.53 \pm 0.02$ & $0.133 \pm 0.005$ \\
\hline 3 & Hardened soya-bean oil & $6 \cdot 4$ & 0.2 & 0.37 & 3 & $0.62 \pm 0.03$ & $0.157 \pm 0.007$ \\
\hline 4 & Hardened soya-bean oil & $\mathrm{I} \cdot 8$ & 0.0 & 0.32 & 3 & $0.68 \pm 0.03$ & $0.159 \pm 0.009$ \\
\hline 5 & Hardened soya-bean oil & $I-8$ & 0 & 0.45 & 4 & $0.73 \pm 0.05$ & $0.150 \pm 0.010$ \\
\hline 6 & Coconut oil & 1.8 & 0.0 & 0.59 & 3 & $0.79 \pm 0.03$ & $0.152 \pm 0.006$ \\
\hline 7 & Hardened soya-bean oil & $2 \cdot I$ & 0.0 & 0.70 & 4 & $0.83 \pm 0.05$ & $0.167 \pm 0.010$ \\
\hline 8 & Commercial diet & 10.5 & 0.2 & $3 \cdot 4$ & 3 & $0.61 \pm 0.07$ & $0.122 \pm 0.014$ \\
\hline 9 & Commercial diet & $15 \cdot r$ & $2 \cdot I$ & $5 \cdot 0$ & 6 & $0.65 \pm 0.04$ & $0.135 \pm 0.008$ \\
\hline & Skimmed colostrum $†$ & $4 \cdot 4$ & 0.1 & $<0.02$ & - & - & 二 \\
\hline
\end{tabular}

Values obtained with diets $I$ and 2 differed significantly from those obtained with diets $3-7$ with respect to daily wt gain $(P<0.01)$ and wt gain/calorie intake $(P<0.01)$.

* Mean values and standard deviations.

+ Fat content less than $0.2 \%$.

RESULTS

\section{Experiments with calves}

The results for growth and energy utilization for the calves on the various experimental diets are presented in Table 2 . The weight gain increased linearly with the calorie content of the diets (given in Table I). However, the weight gain per unit energy intake was lower for diets I and 2, containing 0.2 and $0.4 \%$ fat, respectively, than for the experimental diets $3-7$, which contained $2.5-17.0 \%$ fat. The energy utilization by calves on the two commercial milk replacers 8 and 9 was also low and 
close to the values obtained for diets $\mathbf{I}$ and 2. The commercial products provided much higher levels of linoleic acid compared to the experimental diets but, since they also differed from the latter with respect to other ingredients, it is not possible to relate the results obtained with them to the fatty acid components only.

FA profiles were determined in erythrocytes, and plasma phospholipids and cholesteryl esters at various times. The main PUFA were linoleic and arachidonic acids, with only small amounts of $18: 3$ being present in blood lipids. The triene 20:3 09 was at no time detected in any of the blood lipids. Tissue lipids were examined in a calf on diet 5 which was slaughtered after $1 x_{5} \mathrm{~d}$ (see below); no 20:3 was detected.

Table 3. Mean concentrations (\% of total fatty acids up to and including 20:4) of $18: 2+20: 4$ in blood lipid fractions of calves* after $65 d$ on experimental diets

\begin{tabular}{|c|c|c|c|c|c|c|c|c|c|c|}
\hline \multirow[b]{2}{*}{ Lipid fraction } & \multirow{2}{*}{$\begin{array}{l}\text { Concen- } \\
\text { tration } \\
\text { at birth }\end{array}$} & \multicolumn{9}{|c|}{ Concentration after $6_{5} \mathrm{~d}$ on diet no.: } \\
\hline & & $\mathbf{I}$ & 2 & 3 & 4 & 5 & 6 & 7 & 8 & 9 \\
\hline Plasma cholesteryl esters & $\mathrm{II} \cdot 5$ & $2 I \cdot 3$ & $27 \cdot 6$ & $48 \cdot 9$ & $52 \cdot 8$ & $5^{6 \cdot 5}$ & $67 \cdot 7$ & $\mathrm{ND}$ & $73 \cdot 5$ & $74 \cdot 3$ \\
\hline Plasma phospholipids & Ir.9 & 15.5 & $18 \cdot 7$ & $24 \cdot 5$ & $24 \cdot 6$ & $25^{-8}$ & $25 \cdot 6$ & ND & $29 \cdot 0$ & $32 \cdot 9$ \\
\hline Erythrocytes & $10 \cdot 3$ & 16.7 & $18 \cdot 0$ & 19.0 & $20 \cdot 3$ & $22 \cdot 2$ & 243 & $27 \cdot 4$ & $29 \cdot 6$ & $34 \cdot 2$ \\
\hline Subcutaneous triglycerides & $\mathrm{ND}$ & 3.7 & $4 \cdot 4$ & $5 \cdot 1$ & 5.0 & $5^{\cdot 2}$ & ND & ND & $8 \cdot 2$ & $9^{6} 6$ \\
\hline
\end{tabular}

Table 3 gives the concentrations of EFA (I8:2+20:4) in several blood lipid fractions and in subcutaneous fat of the calves after $65 \mathrm{~d}$ (an essentially similar picture was obtained also when the feeding was continued beyond this age; see also Fig. I). The PUFA concentrations in the blood lipids generally rose with increasing dietary linoleic acid, and this trend was particularly evident in groups given the diets containing the higher range of linoleic acid. In those with the lower dietary range however, this relation was much less clear: in groups 2-4, where the supply of linoleic acid was low and rather similar, blood PUFA levels appeared to rise with increasing dietary fat content. Values for subcutaneous fat included in Table 3 showed a generally similar trend.

\section{Experiments with rats}

In view of the steady increases in EFA concentrations in the lipid fractions even with diets low in EFA, some of the diets used were also given to rats. It is seen from Table 4 that diets 4 and 5 produced a $20: 3$ to $20: 4$ ratio of 0.4 or higher in liver phospholipids and heart muscle FA within $65 \mathrm{~d}$. This is the threshold which, according to Holman ( 1960 ), indicates EFA deficiency. Addition of safflower-seed oil completely prevented the appearance of $20: 3^{\omega 9}$, which was also absent when the diet was rat chow.

In another experiment, diets I and 4 were given to the rats, and the various blood lipid fractions were examined at different times. Table 5 shows that, within $17 \mathrm{~d}$, diet I caused elevated 20:3 to 20:4 ratios in plasma phospholipids, indicating deficiency, and diet 4 did so within $30 \mathrm{~d}$. The addition of safflower-seed oil to diet $\mathbf{I}$ completely prevented the appearance of $20: 3 \omega 9$. 
Table 4. Essential fatty acid status of rats receiving experimental diets for 65 d after weaning

(Mean values for five rats/group)

\begin{tabular}{|c|c|c|c|c|}
\hline \multirow[b]{2}{*}{ Diet } & \multirow{2}{*}{$\begin{array}{c}\text { Dietary } \\
\text { linoleic } \\
\text { acid } \\
\text { (\% of calories) }\end{array}$} & \multirow{2}{*}{$\begin{array}{c}\text { Linoleic acid } \\
\text { content of liver } \\
\text { phospholipid } \\
\text { (\% of } \\
\text { total fatty acids) }\end{array}$} & \multicolumn{2}{|c|}{ Ratio, $20: 3^{\omega g}$ to $20: 4^{\omega 6}$} \\
\hline & & & $\begin{array}{c}\text { Liver } \\
\text { phospholipids }\end{array}$ & $\begin{array}{l}\text { Heart muscle } \\
\text { fatty acids }\end{array}$ \\
\hline I & 0.01 & $\mathbf{I} \cdot 3$ & $2 \cdot 72$ & $I \cdot 59$ \\
\hline 4 & 0.32 & $9 \cdot 1$ & 0.83 & 0.60 \\
\hline 5 & 0.45 & II $\cdot 8$ & $0 \cdot 48$ & 0.37 \\
\hline 7 & 0.70 & 16.6 & $0.1 I$ & 0.09 \\
\hline $\begin{array}{l}5+0.9 \% \text { safflower- } \\
\text { seed oil }\end{array}$ & $I \cdot 0$ & $19 \cdot 8$ & 0.00 & 0.00 \\
\hline Rat chow & $9 \cdot 2$ & $26 \cdot I$ & 0.00 & 0.00 \\
\hline
\end{tabular}

Table 5. Ratio of triene to tetraene in blood lipids of rats receiving the experimental diets at various times after weaning

(Mean values for four rats/group)

Ratio, $20: 3 \omega 9$ to $20: 4 \omega 6$ on diet no.:

Lipid fraction

Plasma phospholipids

Plasma cholesteryl esters

$\begin{array}{ll} & \mathbf{1} 7 \\ & 30\end{array}$

Erythrocytes

\section{Days after} weaning

17
30
50
17
30
50

I 7

30

50

(o

$\left(\begin{array}{c}I \\ (0.01) \dagger\end{array}\right.$

$$
0.83
$$

$\mathrm{r} \cdot 78$

$2 \cdot 02$

0.33

$\mathrm{I} \cdot 92$

2.50

0.17

0.54

0.59

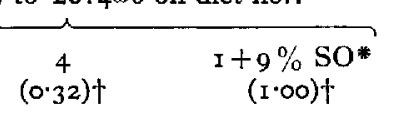

0.29

0.77

0.86

0.10

0.76

0.92

0.02

0.22

0.27
0.14
0.00
0.00
0.06
0.05
0.02
0.00
0.02
0.00

* SO, safflower-seed oil. † Dietary $18: 2$ as \% calories.

Comparison of results from calves and rats

A comparison of the changes observed in the levels of $18: 2+20: 4$ in various blood lipid fractions of calves and rats is presented in Fig. I. Calves were given the diets from birth and rats from weaning. In all calves, there was a rapid rise in blood PUFA during the first few days after birth. At the low dietary linoleic acid levels, this was followed by a fall and a subsequent slower rise. When the linoleic acid supply was high, the initial increase in PUFA continued until steady levels were reached. In contrast to the total rise in blood PUFA observed in calves, the diets low in linoleic acid ( 0.01 and $0.32 \%$ of the total calories) when given to rats caused an immediate decline in the PUFA concentration of plasma phospholipids and cholesteryl esters and in erythrocytes.

One of the calves on diet $5(0.45 \%$ of the calories as linoleic acid) was slaughtered after I $5 \mathrm{~d}$, and the FA composition of various tissues and lipid fractions was determined. Similar analyses were carried out on two calves which died accidentally during 
birth. The following results were obtained for the $18: 2+20: 4$ contents in the newborn calves (mean values) and the Ir 5 -d-old calf, respectively ( $\%$ of total FA): erythrocytes, IO. 3 and $22 \cdot 2$; plasma phospholipids, II $\cdot 9$ and $26 \cdot 2$; plasma cholesteryl esters, II.5 and 57.5 ; heart muscle, 8.5 and 35.3 ; liver phospholipids, 18.5 and 24.9 ; and muscle phospholipids, $16 \cdot 2$ and $21 \cdot 0$. The body-weights at birth averaged $39 \mathrm{~kg}$, and for the

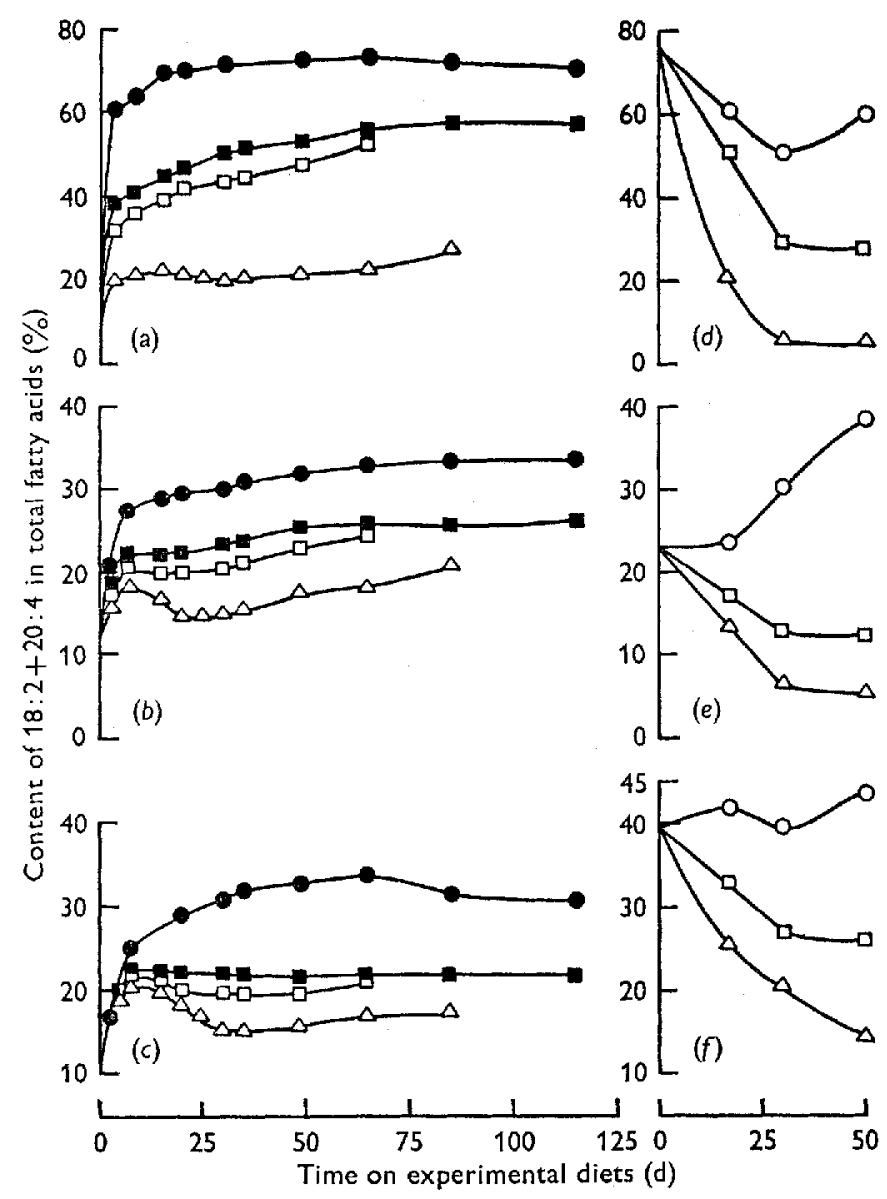

Fig. I. Comparison of changes in linoleic + arachidonic acids of blood lipid fractions of young calves and rats on experimental diets. (a) Calf plasma cholesteryl esters; (b) calf plasma phospholipids; $(c)$ calf erythrocytes; $(d)$ rat plasma cholesteryl esters; $(e)$ rat plasma phospholipids; $(f)$ rat erythrocytes. Linoleic acid intake (as \% of total calories): 5.00 (diet 9); O, I.00 (diet I +0.9\% safflower-seed oil); $\square, 0.45$ (diet 5); $\square, 0.32(\operatorname{diet} 4) ; \triangle, 0.01$ (diet I). Each point represents the mean for three to six calves (see Table 2 ) or four rats.

I I5-d-old calf, it was I I2 kg. Thus these results, although of limited scope, provide an additional indication that the calf given a liquid diet low in linoleic acid accumulates PUFA in its lipids. The average amount of linoleic acid eaten by this calf per $\mathrm{kg}$ increase in body-weight was about $3 \mathrm{~g}$. In contrast the same diet 5 given to rats led to a decrease in EFA concentration and the appearance of $20: 3 \omega 9$, and this in spite of the fact that the calculated intake of $18: 2$ per $\mathrm{kg}$ increase in body-weight in rats was three times greater than in calves. 


\section{DISCUSSION}

In the present study, newborn calves received seven experimental liquid diets supplying linoleic acid in amounts ranging from 0.0 r to $0.7 \%$ of the dietary calories, and two commercial milk replacers in which linoleic acid constituted 3.4 and $5.0 \%$ of the calories. The amounts of linoleic acid supplied by the experimental diets $\mathrm{I}-7$ were all below the value considered to represent the minimum requirement for linoleic acid for many non-ruminant species, namely I \% of the calorie intake (Holman, 1970). Indeed, some of the experimental diets, when given to rats, caused depletion of EFA in blood and tissues and appearance of $20: 3 \omega 9$. The opposite picture was obtained in calves: increases in EFA concentrations were observed in erythrocyte lipids and in plasma phospholipids and cholesteryl esters, especially during the first few days (Fig. I). No 20:3 09 was detected and the growth rates were good.

It is possible that a milk powder with a lower fat content than diet I might have caused a more severe growth depression, as well as changes in FA composition usually associated with the development of EFA deficiency. Such was the case in the work by Noble $e t$ al. (1971), in which one group of lambs received a reconstituted milk powder containing $0.03 \%$ fat during the first $8 \mathrm{~d}$ of life. The present results nevertheless show that pre-ruminant calves must have a considerably lower requirement for linoleic acid than do non-ruminant animals. Noble et al. (1971) reached a similar conclusion from their studies on the composition of plasma lipids in suckling lambs: there were pronounced increases in EFA concentrations in plasma, although the ewes' milk provided subminimal amounts of linoleic acid, according to the criteria applied to non-ruminant species.

Although both total fat and EFA content varied from diet to diet, and strict separation between the influences exerted by these two factors was not possible, certain comparisons could be made. For instance, comparison between groups 2, 3 and 4 (Table 3) shows that, within a narrow range of dietary linoleic acid concentrations, the EFA concentrations in blood and tissue lipids tended to increase with increasing dietary fat content. Also, the diets causing particularly low EFA concentrations in plasma and subcutaneous fat were those in which the fat content was very low (diets I and 2). Thus, it appears that, at low dietary linoleic acid intakes, the amount of total fat in the diet influences the levels of EFA in blood and tissues of calves.

Apart from its role as a source of EFA, dietary fat is known to cause a rapid rise in the concentrations of various plasma lipid fractions of lambs and calves. Thus, it was shown by Noble $e t$ al. (1971) that plasma lipids in newborn lambs given a reconstituted milk powder very low in fat during the first $8 \mathrm{~d}$ tended to fall or remained low, whereas suckling lambs exhibited rapid increases in the concentrations of the same plasma lipids. Similarly, Leat (1967) reported that plasma lipid fractions in suckling lambs rose after birth and reached a maximum between 20 and $30 \mathrm{~d}$, the concentrations then falling slightly but remaining well above those at birth. A similar rise for total plasma lipids was reported earlier in calves by Allen (1938). It is probable that the establishment of adequate concentrations of plasma lipoproteins in the pre-ruminant animal during its early life is important for normal development and that minimal 
amounts of dietary fat must be supplied for this purpose. Work by Lambert $e t$ al. (1954), Cunningham \& Loosli (I954 $a, b$ ) and Adams et al. (I959) appears to support the beneficial effect of dietary fat on growth, other than as a source of EFA.

The FA composition of blood and tissue lipids reported in the present study was determined by gas-liquid chromatography. The values for linoleic acid thus obtained could conceivably include positional and geometrical isomers, which are known to be present in hydrogenated oils and in milk fat. The lipoxygenase test, which is specific for PUFA containing the 1,4 -cis,cis-pentadiene system, revealed that such isomers amounted to less than $10 \%$ of the total dietary octadecadienoic acid as determined by gas-liquid chromatography. It is unlikely that the percentage of linoleic acid isomers present in calves in these experiments was greater than that found in the diets, especially in view of the similarity between the digestive processes in very young ruminants and non-ruminant animals.

The apparently low requirement of pre-ruminant calves for EFA has not yet been explained, and this question is the more intriguing as the newborn calf, which possesses low EFA reserves compared with the weanling rat (Fig. I) would be expected to be more susceptible to the induction of EFA deficiency. In view of the results of the comparative rat experiments, it might be suspected that calves possess a particularly efficient mechanism for conserving EFA. There is no evidence to support this assumption, and we have noted that the calf wastes EFA through the sebaceous skin secretions. A possible sparing effect by saturated FA in vivo must be ruled out, since the exact opposite, namely increased severity of EFA deficiency signs, has been reported in rats (Alfin-Slater, Morris, Hansen \& Proctor, 1965).

The possibility that the straw used as a bedding material might have contributed significant amounts of linoleic acid in the present experiments, because of nibbling, should be considered. The straw contained $230 \mathrm{mg}$ linoleic acid $/ \mathrm{kg}$. Direct observation of nibbling behaviour and examination of stomach contents at different times indicated that the quantity of straw eaten, even towards the end of the experimental period, was too small to supply significant amounts of linoleic acid relative to those provided by the diets.

We have recently reported that aerobic incubation of fluid taken from the immature rumens of calves on milk diets results in the formation of octadecadienoic acid at the expense of more saturated $\mathrm{C}_{18}$ acids (Sklan et al. 1971). The possibility therefore exists that a similar process takes place in the immature rumen and supplies EFA to the calf. This would explain the apparent lack of susceptibility of calves to diets low in EFA, the beneficial effect produced by saturated fats at low EFA levels observed in the present study and in work by others cited above, and the increase in EFA concentrations in blood and tissue lipids of calves maintained on milk diets low in EFA. Further work is needed to substantiate this explanation.

We thank Ofra Kedar for skilled technical assistance. 


\section{REFERENCES}

Adams, R. S., Gullickson, T. W., Gander, J. E. \& Sautter, J. H. (r959). F. Dairy Sci. 42, I552. Alfin-Slater, R. B., Morris, R. S., Hansen, H. \& Proctor, J. F. (т965). F. Nutr. 87, i68.

Allen, N. N. (1938). Tech. Bull. Mim. agric. Exp. Stn no. 130.

Cunningham, H. M. \& Loosli, J. K. (1954a). F. Dairy Sci. 37, 453.

Cunningham, H. M. \& Loosli, J. K. (1954b). F. Anim. Sci. 13, 265.

Dodge, J. 'T. \& Phillips, G. B. (1967). F. Lipid Res. 8, 667.

Folch, J., Lees, M. \& Stanley, G. H. S. (1957). F. biol. Chem. 226, 497.

Holman, R. T. (1960). F. Nutr. 7o, 405.

Holman, R. T. (I970). In Progress in the Chemistry of Fats and Other Lipids Vol. 9, Patt 4, p. 665 [R. T. Holman, editor]. Oxford: Pergamon Press.

Lambert, M. R., Jacobson, N. L., Allen, R. S. \& Zaletel, J. H. (1954). F. Nutr. 52, 259.

Leat, W. M. F. (1966). Biochem. \%. 98, 598.

Leat, W. M. F. (1967). 7. agric. Sci., Camb. 69, 241.

MacGee, J. (1959). Analyt. Chem. 31, 298.

Noble, R. C., Steele, W. \& Moore, J. H. (I971). Lipids 6, 26.

Sklan, D., Volcani, R. \& Budowski, P. (197r). F. Dairy Sci. 54, 515.

Viviani, R. (1970). Adv. Lipid Res. 8, 824 . 